\title{
RENEWABLE ENERGY CONTENT OF FATTY ACID METHYL ESTERS (FAME) AND GLYCEROL
}

\author{
Giuseppe Toscano, Daniele Duca
}

\section{Introduction}

In recent years, there have been many reasons that have encouraged the European Parliament to endorse support actions and incentives for the development of renewable Energy [Parish 2006]. Electricity production and transport are among the most interesting sectors affected by Directives 2001/77/EC and 2003/30/EC as well as the additional 2003/96/CE which applies to both sectors. One of the products, particularly affected by these actions, is FAME, known as biodiesel. Its characteristics are specified in two provisions that have been active since 2003 in Europe and since 2004 in Italy: the UNI EN 14213 "Heating fuels. Requirements and test methods" and the UNI EN 14214 - "Automotive fuels. Fatty acid methyl esters (FAME) for diesel engines. Requirements and test methods".

Taking into account biofuel, FAME is the only product produced by a chemical process based on the reaction between the glycerides present in vegetable oil and a product from a fossil source: methanol. Besides FAME, which is made up of a mixture of methyl esters (ME), the process generates a reaction by-product, glycerol (GL), which is also used as a bio-fuel. Both the molecules produced contain atoms from the methanol within the reagent and, therefore, are not considered renewable. Given that they are energy products produced from a reaction between a renewable material and a fossil source, it is necessary to define the renewable energy they contain, for instance, this is necessary when applying the biomass incentives according to the European provisions and for testing the biofuels and the bioliquids required by the new Directive 2009/28/CE (RED). In this manner, the

Paper received 15.07.2009; accepted 23.09.2009

Dott. GIUSEPPE ToscANo researcher, Dept. SAIFET, Technical University of Marche, g.toscano@univpm.it; Dott. DANIELE DucA, PhD student, Dept. SAIFET, Technical University of Marche, d.duca@univpm.it latter will therefore provide a methodological and practical contribution. Generally, the heat produced by a reaction (combustion is a reaction) can be estimated through experiments (calorimeter) or, indirectly, by calculating the reaction enthalpies. The overall energy developed from a complete molecule combustion can be measured experimentally with the calorimetric method. Nevertheless, this method does not indicate the extent to which each molecule part contributes to the heat produced. The indirect methods involve calculation procedures, which are based on precise information about the reaction and the thermochemical data of the molecules or the parts involved.

One of the most diffused indirect methods is based on the knowledge about the enthalpy formation of the reagents and the products involved in the reaction [Chambers 1975, Lanfred 2001]. In any case, in the absence of data about complex molecules various strategies are used to calculate the reaction enthalpy of a chemical process using the Benson group additive method [Nomen 2005]. This method is based on the precise knowledge of the molecular structures involved in the reaction and the identification of the group of atoms consists of at least two chemical bonds [Chopey 2004]. Besides being an easily applicable approach, it can usually predict thermochemical data with the same uncertainty of experiments [Aa.Vv. 2004]. Nevertheless, neither calculation modality allows the estimation of the energy contributed by the single atom. There is also another method based on the knowledge of the reagent and the product molecular structure and bond enthalpy $\left(\Delta H_{b}\right)$ or of bond dissociation energies which is very immediate. The $\Delta H_{b}$ is a positive number corresponding to the energy required to break the molecule into its fragments, or the energy released when the bond is formed [Salmon 2006]. All materials are made of atoms which are tightly bonded to each other to form molecules of the materials. When a chemical reaction occurs, the materials change into other materials through bond breakage and new bond formation [Kubota 2002]. Any chemical reaction, including combustion, starts with a first phase of bond breaking within the reagent molecule, which requires the ab- 
sorption of the heat system $\Delta H_{b r}$, concluding with a second phase of new bond formation of products in which $\Delta H_{b p}$ heat develops. The energetic balance of both enthalpies determines the heat of the $\Delta H_{r}$ reaction (1). In particular:

$$
\Delta H_{r}=\Delta H_{b p}-\Delta H_{b r}
$$

When the $\Delta H_{r}$ of the reaction is negative, the reaction is exothermic, as in the case of combustion.

The $\Delta H_{b}$ depends on the type and the energetic state of the atoms based on the electron of each atom. Although the exact energetic state of the materials should be evaluated by quantum mechanics, an overall energetic state is evaluated by the $\Delta H_{b}$ determined experimentally. The total chemical bond energy of the molecule atoms is equal to the energy of the molecule [Kubota 2002].

Considering the aspects mentioned in the introduction and according to the analysis regarding the energy aspects of the chemical reactions, it was considered interesting to develop a method for calculating the content of the renewable energy fraction in GL and FAME products using the traditional process based on the transesterification reaction. In other words, the degree of renewability of the chemically modified generated biomass products can be calculated using this method. At the same time the amount of energy produced from their combustion and which can be attributed to the initial biogenic matter can also be estimated. A calculation criteria, backed with simplified analytic measurements, is especially used for the FAME products. This method might be useful in understanding the various energy contents in other similar renewable energy products. Besides FAME, there are other synthesis products derived from renewable and non-renewable materials. An example of this is the Ethyl Tertiary Butyl Ether (ETBE). On the contrary, the production of ethyl esters from renewable ethanol ensures the renewability of the products. Nevertheless, there is still no comparative criterion for product renewability. The aim of this study is to fill up this gap.

\section{Material and methods}

This study was developed and presented in two distinct parts: the calculation methodology to estimate the renewable energy content in FAME and GL and the development of an applied analysis method for FAME.

\subsection{Remarks on transesterification reactions}

This equation is for a simplified form of a transesterification reaction (figure 1 ) where $\mathrm{R}_{1}, \mathrm{R}_{2}$, and $\mathrm{R}_{3}$ are long chains of carbons and hydrogen atoms, called the fatty acid chain. Two of the most commonly used

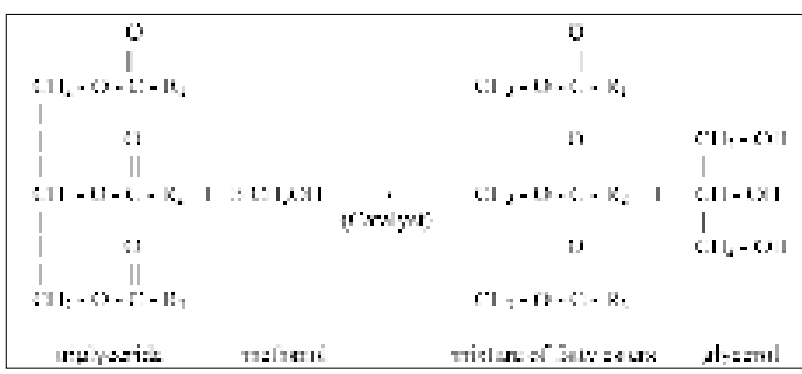

Fig. 1 - Transesterification reaction chart (processed by Van Gerpen)

catalysts for transesterification are $\mathrm{NaOH}$ and $\mathrm{KOH}$. The reaction mechanisms can vary according to the conditions of the reaction [Van Jerpen 2004].

Nevertheless, it is possible to identify the methanol molecule in the reaction products through a mechanism of mass balancing in the simplified reaction, i.e., the methoxide added to the carboxyl of the ME and the hydrogen in the functional group -OH of the GL. Analyzing the chemical bonds in the ME it is possible to consider the derivatives from the methanol $3 \mathrm{C}-\mathrm{H}$ bonds and the $\mathrm{C}-\mathrm{O} 1.5$ bonds as well as half the $\mathrm{O}-\mathrm{H}$ bond in GL. This analysis is fundamental to establish which bonds contribute to identify the non-renewable and renewable energetic fraction of the produced $\Delta H_{r}$.

\subsection{Analysis of the combustion reaction and the calculation of the non-renewable energetic fraction}

The complete combustion of ME and GL is defined by the generic reactions (I and II), respectively:

$$
\begin{aligned}
& \mathrm{C}_{(n)} \mathrm{H}_{(2 n-2 s)} \mathrm{O}_{2}+(n-1+(n-s) / 2) \mathrm{O}_{2} \rightarrow(n) \mathrm{CO}_{2}+ \\
& +(n-s) \mathrm{H}_{2} \mathrm{O} \\
& \mathrm{C}_{3} \mathrm{H}_{8} \mathrm{O}_{3}+7 / 2 \mathrm{O}_{2} \rightarrow 3 \mathrm{CO}_{2}+4 \mathrm{H}_{2} \mathrm{O}
\end{aligned}
$$

in which $n$ is the number of carbon atoms of ME and $s$ is the number of unsaturations present. Given the structure of the molecule and in function of $n$ and $s$, it is possible to calculate the total number of the various chemical bonds forming the reagent molecules and the reaction products. Only three elements are involved in the structure of the molecule: carbon, hydrogen and oxygen. As regards to the reagents, on the one hand these elements are found in the bonds $\mathrm{C}-\mathrm{C}$ and $\mathrm{C}-\mathrm{H}$, forming a carbonaceous chain and the methyl of the methoxide group in the ME and the entire carbonaceous structure of the GL; on the other hand, the bonds $\mathrm{C}=\mathrm{O}$ and $\mathrm{C}-\mathrm{O}$ form the carboxyl group of the fatty acids and the bond $\mathrm{O}=\mathrm{O}$ forms the oxygen. Within the reaction products, combustion water and carbon dioxide, the bonds are represented by $\mathrm{O}-\mathrm{H}$ and $\mathrm{C}=\mathrm{O}$. Some of these bonds are hybrids, that is, consisting of an atom that is originally present in the triglyceride and another atom originally present in methanol. The value of $\Delta H_{b}$ has been defined for 
every bond, based on literature, with reference to the molecules or functional groups that most resemble the ones at issue in this study. Moreover, the member molecule in the combustion reaction and the number of bonds formed from a generic ME (table 1) and GL (table 2) were indicated together with other data.

\subsection{Reaction energy calculation}

From (1) it is possible to determine the general calculation equations for combustion $\Delta H_{r}$ for every product considered. In the case of $\mathrm{ME}$ and GL, the calculation of $\Delta H_{r}$ is described in table 3.
Theoretically, the value of $\Delta H_{r}$ coincides with the high calorific value of the product. The energetic $\Delta H_{i}$ value is determined by subtracting the enthalpy of water evaporation generated in combustion $\left(H_{E}=40.7\right.$ $\mathrm{kJ} / \mathrm{mol}$ ), theoretically expressing the low calorific value. In particular:

$$
\begin{gathered}
\Delta H_{i(M E)}=\Delta H_{r(M E)}-(n-s) \times H_{E^{-}} \\
\Delta H_{i(G L)}=\Delta H_{r(G L)}-4 \times H_{E}
\end{gathered}
$$

The same calculation criteria, described above for the atoms at issue, can be used to calculate the en-

\begin{tabular}{|l|c|c|c|c|}
\hline Bond & Bibliographic reference & $\Delta H_{b}(\mathrm{~kJ} / \mathrm{mole})$ & $\begin{array}{c}\text { Affected } \\
\text { molecule }\end{array}$ & $\begin{array}{c}\text { Bond } \\
(\mathrm{n})\end{array}$ \\
\hline $\mathrm{C}-\mathrm{H}$ & (Lide 1999) - Propane & 423 & $\mathrm{ME}$ & $2 \mathrm{n}-2 \mathrm{~s}$ \\
\hline $\mathrm{C}-\mathrm{C}$ & $\begin{array}{c}\text { (Kubota 2002), (Lide 1999) } \\
\text { (Silvestroni 1984) - Average value }\end{array}$ & 367 & $\mathrm{ME}$ & $\mathrm{n}-\mathrm{s}-2$ \\
\hline $\mathrm{C}=\mathrm{O}_{(\mathrm{I})}$ & (Kubota 2002) - Ketone & 766 & $\mathrm{ME}$ & 1 \\
\hline $\mathrm{C}-\mathrm{O}$ & (Kubota 2002) - Generic & 350 & $\mathrm{ME}$ & 2 \\
\hline $\mathrm{C}=\mathrm{C}$ & (Kubota 2002) - Generic & 599 & $\mathrm{ME}$ & $\mathrm{S}$ \\
\hline $\mathrm{O}=\mathrm{O}$ & (Kubota 2002) - Oxygen & 498 & $\mathrm{O}_{2}$ & $\mathrm{n}-1+(\mathrm{n}-\mathrm{s}) / 2$ \\
\hline $\mathrm{C}=\mathrm{O}_{(\mathrm{II})}$ & $($ Hueey 1983) - Carbon dioxide & 803 & $\mathrm{CO}_{2}$ & $2 \mathrm{n}$ \\
\hline $\mathrm{O}-\mathrm{H}_{(\mathrm{I})}$ & (Lide 1999) - Water & 497 & $\mathrm{Water}$ & $2(\mathrm{n}-\mathrm{s})$ \\
\hline
\end{tabular}

TABLE 1 - Enthalpic characteristics and the main data on chemical bonds in ME combustion.

\begin{tabular}{|l|c|c|c|c|}
\hline Bond & Bibliographic reference & $\Delta H_{b}(\mathrm{~kJ} / \mathrm{mole})$ & $\begin{array}{c}\text { Affected } \\
\text { molecule }\end{array}$ & $\begin{array}{c}\text { Bond } \\
(\mathrm{n})\end{array}$ \\
\hline $\mathrm{C}-\mathrm{H}$ & (Lide 1999) - Propane & 423 & $\mathrm{GL}$ & 5 \\
\hline $\mathrm{C}-\mathrm{C}$ & $\begin{array}{c}\text { (Kubota 2002), (Lide 1999), } \\
\text { (Silvestroni 1984) - Average value }\end{array}$ & 367 & $\mathrm{GL}$ & 2 \\
\hline $\mathrm{C}-\mathrm{O}$ & (Kubota 2002) - Generic & 350 & $\mathrm{GL}$ & 3 \\
\hline $\mathrm{O}-\mathrm{H}_{\text {(II) }}$ & (Lide 1999) - Ethanol & 438 & $\mathrm{GL}$ & 3 \\
\hline $\mathrm{O}=\mathrm{O}$ & (Silvestroni 1984) - Oxygen & 498 & $\mathrm{O}_{2}$ & 3.5 \\
\hline $\mathrm{C}=\mathrm{O}_{(\mathrm{II})}$ & (Hueey 1983) - Carbon dioxide & 803 & $\mathrm{CO}_{2}$ & 6 \\
\hline $\mathrm{O}-\mathrm{H}_{(\mathrm{I})}$ & (Lide 1999) - Water & 497 & $\mathrm{Water}$ & 8 \\
\hline
\end{tabular}

TABLE 2 - Enthalpic characteristics and the main data on chemical bonds in GL combustion.

\begin{tabular}{|c|c|}
\hline Product & Calculation of $\Delta H_{r}$ \\
\hline \multirow{2}{*}{ Methyl ester } & $\begin{array}{l}\Delta H_{r(\mathrm{ME})}=\left(2 n \_\Delta H_{C=O(I I)}+2(n-s) \_\Delta H_{O-H(I)}\right)-\left((2 n-2 s) \_\Delta H_{C-H}+(n-s-2) \_\Delta H_{C-C}+\Delta H_{C=O(I)}+2 \_\Delta H_{C-O}+\right. \\
\left.s_{-} \Delta H_{C=C}+(n-1+(n-s) / 2) \_\Delta H_{O=O}\right)\end{array}$ \\
\hline Glycerol & $\Delta H_{r(G L)}=\left(6 \_\Delta H_{C=O(I I)}+8 \_\Delta H_{O-H(I)}\right)-\left(5 \_\Delta H_{C-H}+2 \_\Delta H_{C-C}+3 \_\Delta H_{C-O}+3 \_\Delta H_{O-H(I I)}+3.5 \_\Delta H_{O=O}\right)(3)$ \\
\hline
\end{tabular}

TABLE 3 - Calculation of $\Delta \mathrm{H}_{\mathrm{r}}$ for ME and GL. 
thalpy from the non-renewable part of the molecule $\left(\Delta H_{N R}\right)$. The following equations were used:

$$
\begin{aligned}
& \Delta H_{r N B(M E)}=\left(1.5 \times \Delta H_{C-O X M)}+1.5 \times \Delta H_{O-H(l)}\right)-(6) \\
& \left(3 \times \Delta H_{C-H}+1.5 \times \Delta H_{C-O}\right) \\
& \Delta H_{H \times R(G L)}=\left(1.5 \times \Delta H_{O-H(J)}\right)-\left(1.5 \times \Delta H_{O-H(I)}\right) \\
& \Delta H_{\text {iNR(ME) }}-\Delta H_{\text {NW(ME) }}-1.5 \times H_{E}
\end{aligned}
$$

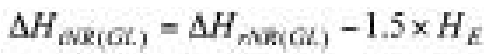

The fraction of non-renewable energy of the molecule $\left(E_{N R}\right)$ is obtained from the ratio of $\Delta H_{i N R}$ and $\Delta H_{i}$

$$
\begin{aligned}
& E_{\text {NR(FAME) }}=\Delta H_{\text {NRE(ME) }} / \Delta H_{\text {L(FAMEE })} \times J O O \\
& E_{\text {NR(GL) }}=\Delta H_{(N R / G L)} / \Delta H_{S(G L)} \times I 00
\end{aligned}
$$

In order to evaluate the approximation level of the calculation method used, it was considered necessary to compare the calculated $\Delta H_{r}$ values for every FAME with the respective values obtained through experiments $\left(\Delta H_{C}\right)$. The latter are average values deduced from the database of the National Institute of Standard Technology (NIST). For every ME, the absolute error and the percentage error $(\Delta E)$ were calculated with reference to the $\Delta H_{r}$ data obtained through experiments. The estimations were carried out on the ME that mostly represented the corresponding fatty acids of the most common vegetable oils. Considering that FAME is made up of variable mixtures of ME, an average value, which takes into consideration the percentage composition of the $\operatorname{ME}\left(C_{M E}\right)$ and the respective $E_{N R}$ values, must be used to calculate the non-renewable part of the entire $E F_{N R}$ produced. In the case of a generic FAME, the value of $E F_{N R}$ is calculated as follows:

$$
E F_{N R}=\sum\left(E_{N R(M E)_{s}} \times C_{M E}\right) / 100
$$

in which $x$ indicates the generic ME present in FAME.

\subsection{Experimental methods to measure the non-re- newable fraction of FAME}

The proposed calculation method was applied to some products to verify its feasibility. For this purpose, 15 vegetable oil samples were picked from most representative especially in terms of variability in the length of glyceride acid chains. The size of the molecule from fatty acid plays an important role on the fraction of renewability of each ME. Gas-chromatographic analyses were carried out to determine the $C_{M E}$ and to estimate the amount of saponification $\left(N_{S}\right)$.

The number of average carbon atoms $\left(N_{C M}\right)$ of FAME was calculated as follows, taking into consideration the acidic composition and the function of (13):

$$
N_{C M}=\sum\left(N_{C M E)} \times C_{M E}\right) / 100
$$

in which $N_{C}$ is the number of carbon atoms in each ME. The value of $N_{C}$ expresses the average molecule mass of glyceride contents in vegetable oil to be compared with the corresponding FAME. Specifically, each of them was tested for the correlation between $E F_{N R}$ and the $N_{C}$ value. Subsequently, the correlations between the value of $N_{C}$ and that of $N_{S}$ and, finally, between the $E F_{N R}$ values and those of $N_{S}$ were verified.

\section{Results}

Table 4 shows a series of specific results regarding each ME. The data of the $\Delta H_{r}$ calculated with the proposed methodology and the $\Delta H_{c}$ taken from the NIST database are also shown in the table. It has been observed that the $\Delta E$ values are rather contained and consolidated around an average of $0.6 \%$ (corresponding to about $65 \mathrm{~kJ} / \mathrm{mol}$ ) with a maximum of $-2.5 \%$. For the purpose of this study, these results are encouraging and favourably support the proposed calculation method. The $E_{N R}$ values of each ME are also reported in the table. It can be observed that since the amount of energy coming from the non-renewable part of the molecule (methoxide) is constant, the $E_{N R}$ value is strongly dependent on the length of the ME. In unsaturated molecules, the values vary between $2.4 \%$ of ME with 7 carbon atoms and $0.7 \%$ of ME with 23 carbon atoms.

Similarly, table 5 shows the same results obtained for GL. It has been noticed that the $\Delta E$ is higher compared to the calculations carried out on the ME and a little less than $10 \%$ lower. Although the non-renewable part, i.e. hydrogen derived from methanol, always forms a bond $-\mathrm{OH}$ before and after the reaction, the calculated $E_{N R}$ is still equal to $1.6 \%$, taking into consideration that the $-\mathrm{OH}$ bond before and after the reaction has various chemical characteristics and, therefore, different $\Delta H_{b}$ values.

Finally, for all of the 15 vegetable oils, table 6 shows the parameters that mark the average molecular size of the triglyceride mixtures and, therefore, that of FAME generated by them. In addition, there is the $E F_{N R}$ value calculated on the $C_{M E}$ determined for every analysed oil.

On the whole, most oils and, therefore, those related to FAME, have a similar average molecule size, with the exception of brassica and coconut oil which have a shorter and longer carbonaceous chain compared to average chains, respectively. Along with the figures of $N_{C M}$ and $N_{S}$, the $E F_{N R}$ oscillates between $0.78 \%$ and $1.20 \%$. Figure 2 shows the relation between the latter parameter and the $N_{C M}$ figure which emphasises the decrease of the non-renewability of the molecule due to the increase in the length of the carbonaceous chain, the non-renewability of the molecule decreases. This study has confirmed how the $N_{C M}$ figure can be determined through a simple analysis such as saponification number. Figure 3 confirms 


\begin{tabular}{|c|c|c|c|c|c|c|c|}
\hline $\mathrm{ME}$ & $\begin{array}{c}\Delta H_{c} \\
(\mathrm{~kJ} / \mathrm{mol})\end{array}$ & $\begin{array}{c}\Delta H_{r} \\
(\mathrm{~kJ} / \mathrm{mol})\end{array}$ & $\begin{array}{c}\Delta H_{c}-\Delta H_{r} \\
(\mathrm{~kJ} / \mathrm{mol})\end{array}$ & $\begin{array}{c}\Delta E \\
(\%)\end{array}$ & $\begin{array}{c}\Delta H_{i} \\
(\mathrm{~kJ} / \mathrm{mol})\end{array}$ & $\begin{array}{c}\Delta H_{i N R} \\
(\mathrm{~kJ} / \mathrm{mol})\end{array}$ & $\begin{array}{c}E_{N R} \\
(\%)\end{array}$ \\
\hline $\mathrm{C}_{7} \mathrm{H}_{14} \mathrm{O}_{2}$ & 4200 & 4246 & -46.5 & $-1.1 \%$ & 3960 & 95 & $2.4 \%$ \\
\hline $\mathrm{C}_{9} \mathrm{H}_{18} \mathrm{O}_{2}$ & 5509 & 5526 & -17.4 & $-0.3 \%$ & 5159 & 95 & $1.8 \%$ \\
\hline $\mathrm{C}_{11} \mathrm{H}_{22} \mathrm{O}_{2}$ & 6815 & 6806 & 9.4 & $0.1 \%$ & 6357 & 95 & $1.5 \%$ \\
\hline $\mathrm{C}_{13} \mathrm{H}_{26} \mathrm{O}_{2}$ & 8127 & 8086 & 41.4 & $0.5 \%$ & 7556 & 95 & $1.3 \%$ \\
\hline $\mathrm{C}_{15} \mathrm{H}_{30} \mathrm{O}_{2}$ & 9438 & 9366 & 72 & $0.8 \%$ & 8754 & 95 & $1.1 \%$ \\
\hline $\mathrm{C}_{17} \mathrm{H}_{34} \mathrm{O}_{2}$ & 10388 & 10646 & -258 & $-2.5 \%$ & 9952 & 95 & $1.0 \%$ \\
\hline $\mathrm{C}_{19} \mathrm{H}_{38} \mathrm{O}_{2}$ & 11962 & 11926 & 36 & $0.3 \%$ & 11151 & 95 & $0.9 \%$ \\
\hline $\mathrm{C}_{21} \mathrm{H}_{42} \mathrm{O}_{2}$ & 13263 & 13206 & 57 & $0.4 \%$ & 12349 & 95 & $0.8 \%$ \\
\hline $\mathrm{C}_{23} \mathrm{H}_{46} \mathrm{O}_{2}$ & 14565 & 14486 & 79 & $0.5 \%$ & 13548 & 95 & $0.7 \%$ \\
\hline $\mathrm{C}_{25} \mathrm{H}_{50} \mathrm{O}_{2}$ & Not taken & 15766 & --- & --- & 14746 & 95 & $0.6 \%$ \\
\hline $\mathrm{C}_{17} \mathrm{H}_{32} \mathrm{O}_{2}$ & 10548 & 10515 & 33 & $0.3 \%$ & 9862 & 95 & $1.0 \%$ \\
\hline
\end{tabular}

TABLE 4 - Results of the thermochemical analysis on each ME.

\begin{tabular}{|c|c|c|c|c|c|c|c|}
\hline Molecule & $\Delta H_{c}(\mathrm{~kJ} / \mathrm{mol})$ & $\begin{array}{c}\Delta H_{r} \\
(\mathrm{~kJ} / \mathrm{mol})\end{array}$ & $\begin{array}{c}\Delta H_{c}-\Delta H_{r} \\
(\mathrm{~kJ} / \mathrm{mol})\end{array}$ & $\begin{array}{c}\Delta E \\
(\%)\end{array}$ & $\begin{array}{c}\Delta H_{i} \\
(\mathrm{~kJ} / \mathrm{mol})\end{array}$ & $\begin{array}{c}\Delta H_{i N R} \\
(\mathrm{~kJ} / \mathrm{mol})\end{array}$ & $\begin{array}{c}E_{N R} \\
(\%)\end{array}$ \\
\hline $\mathrm{C}_{3} \mathrm{H}_{8} \mathrm{O}_{3}$ & 1657 & 1838 & -181 & -9.8 & 1675 & 27 & 1.6 \\
\hline
\end{tabular}

TABLE 5 - Results of the thermo-chemical analysis on GL.

\begin{tabular}{|c|c|c|c|c|}
\hline Derivation oil & Treatment & $\begin{array}{c}N_{C M(M E)} \\
(\mathrm{n})\end{array}$ & $N_{S}$ & $E F_{N R}$ \\
\hline Soya & Refined & 18.8 & 196.4 & $0.87 \%$ \\
\hline Sunflower & Refined & 18.9 & 191.9 & $0.87 \%$ \\
\hline Brassica carinata & Raw & 21.0 & 177.4 & $0.78 \%$ \\
\hline Coconut & Refined & 14.1 & 259.9 & $1.20 \%$ \\
\hline Rape & Refined & 18.9 & 192.7 & $0.86 \%$ \\
\hline Palm & Refined & 18.1 & 200.6 & $0.90 \%$ \\
\hline Grape seed & Raw & 18.9 & 196.7 & $0.87 \%$ \\
\hline Palm & Raw & 18.0 & 201.6 & $0.90 \%$ \\
\hline Corn & Raw & 18.8 & 193.7 & $0.87 \%$ \\
\hline Soya & Raw & 18.8 & 197.8 & $0.87 \%$ \\
\hline Rape & Raw & 18.9 & 192.6 & $0.86 \%$ \\
\hline Sunflower & Raw & 18.9 & 194.7 & $0.86 \%$ \\
\hline Jatropha & Raw & 18.7 & 195.3 & $0.87 \%$ \\
\hline Sunflower & Fried & 18.9 & 194.3 & $0.87 \%$ \\
\hline Cotton & Raw & 18.5 & 200.8 & $0.89 \%$ \\
\hline
\end{tabular}

TABLE 6 - Values of $\mathrm{N}_{\mathrm{CM}}, \mathrm{N}_{\mathrm{S}}$ and $\mathrm{EF}_{\mathrm{NR}}$ for oils used for work.

this hypothesis and highlights an important analytic relation between the two parameters without using the gas-chromatographic analysis.

As a result of the previous correlations, $N_{S}$ is capable of calculating the $E F_{N R}$ value of a generic FAME (figure 4). The correlation obtained shows a very high $\mathrm{R}^{2}$ value and covers a very important $N_{S}$ field to which most of the FAME diffused on the market belongs.

\section{Conclusion}

The biofuel obtained from the triglyceride transesterification of vegetable oil, using methanol from fossil, englobes the non-renewable energy in its molecules originally released during combustion. The study has shown that for GL, the energetic supply is about $1.6 \%$ of the net energy obtained from combus- 


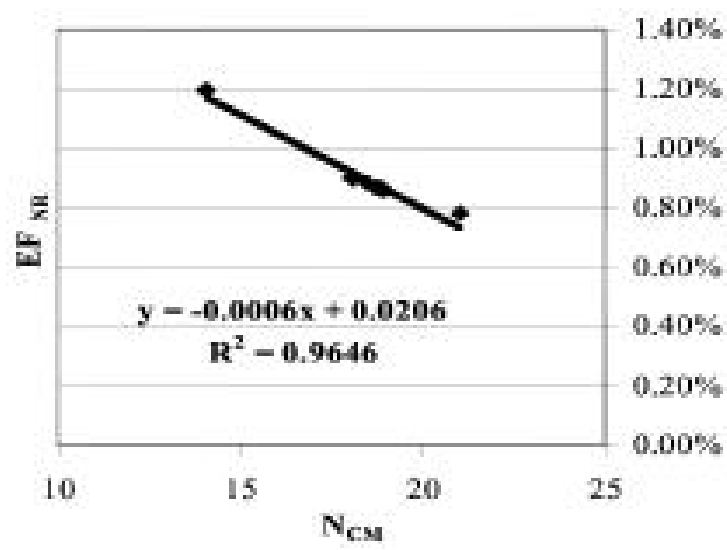

Fig. 2 - Correlation between $\mathrm{EF}_{\mathrm{NR}}$ and $\mathrm{N}_{\mathrm{CM}}$ of FAME.

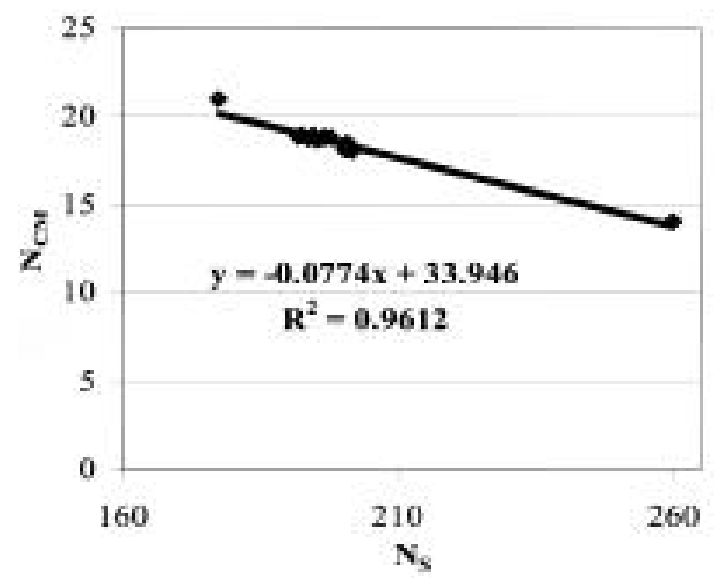

Fig. 3 - Correlation between $\mathrm{N}_{\mathrm{CM}}$ and $\mathrm{N}_{\mathrm{S}}$.

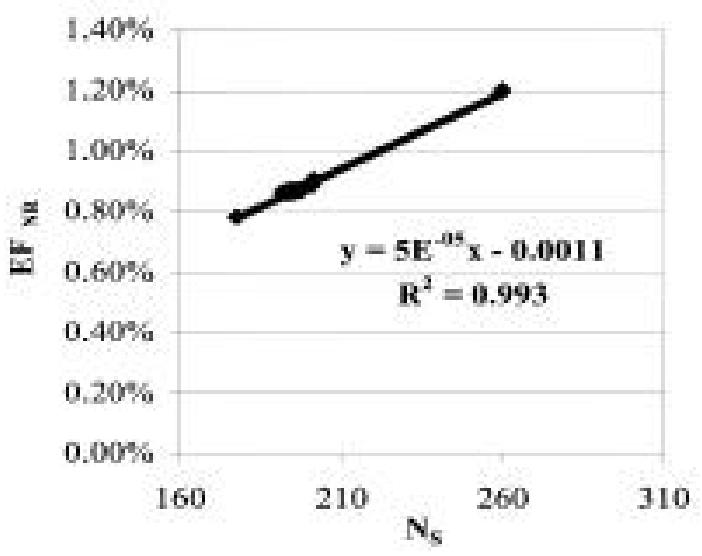

Fig. 4 - Correlations between $\mathrm{EF}_{\mathrm{NR}}$ and $\mathrm{N}_{\mathrm{S}}$.

tion. In the case of FAME, the $E F_{N R}$ value is conditioned by the length of the ME molecules. With the increase in the size of the average ME molecule, the $E F_{N R}$ decreases. The study shows that through the $N_{S}$ value, whose laboratory analytic definition is quite simple, it is possible to provide a rather precise estimation of the $E F_{N}$ when FAME is obtained from various initial vegetal oils. On the whole, the most diffused FAME deriving, for example, from rape, soya and palm oil have an $E F_{N R}$ value lower than $1 \%$. Nevertheless, it is assumed that the $E F_{N R}$ value is unlikely to exceed the $1.5 \%$ threshold which corresponds to the products generated from vegetable oil with carbonaceous chain with an average of 10 carbon atoms. The data reported in this document can be a starting point for the identification of the correction factors for the fiscal aspects and the stimulation mechanism of renewable energy products.

\section{References}

Aa.Vv., Encyclopedia of Physical Science and Technology - Organic chemistry. Third edition, AP editor, 2004.

Chambers C., Holliday A.K. Modern inorganic chemistry. Rhadon, 1975, Great Britain.

Chopey N.P. Handbook of chemical engineering calculations. Third edition, McGrawHill, Digital Engineering library, 2004.

Huheey J.E. Inorganic Chemistry: Principles of Structure and Reactivity. Third Edition, Addison Wesley Longman, 1983.

Kubota N. Propellents and explosive: Thermochemical Aspects of Combustion. Wiley-VCH Verlagh $\mathrm{GmbH} \& \mathrm{CO}$ KGaA, 2002.

Lanfred M., Tiripicchio A. Fondamenti di chimica. Casa Editrice Ambrosiana, 2001, Milano.

Lide D.R. CRC Handbook of Chemistry and Physics. 80th ed., CRC Press, 1999, New York.

Nomen R., Bartra M., Sempere J., Serra E., Sales J., Romero X. The estimation of reaction enthalpy for complex molecules using Benson groups. Journal of Thermal Analysis and Calorimetry, 2005, 82(3), 581-584.

Parish N. Report on the promotion of cultivations for non alimentary purposes - (2004/2259(INI)) - Session Document - Committee for agriculture and rural development - European Parliament- February 2006.

Salmon A., Dalmazzone D. Prediction of Enthalpy of Formation in the Solid State at 298.15 K using Second-Order Group Contributions - Part 1. Carbon-Hydrogen and Carbon-Hydrogen-Oxygen Compounds. J. Phys. Chem. Ref. Data, 2006, 35(3).

Silvestroni P. Fondamenti di chimica, Veschi Editore, 1984, Roma.

UNI EN ISO 3657 - Oli e grassi animali e vegetali - Determinazione del numero di saponificazione.

UNI EN ISO 5508 - Oli e grassi animali e vegetali - Analisi gascromatografica degli esteri metilici degli acidi grassi.

Van Gerpen J, Shanks B., Pruszko R., Clements D., Knothe G. Biodiesel Production Technologies - Subcontracting Reports. National Renewable Energy Laboratory, www.nrel.gov., July 2004.

\section{SUMMARY}

Fatty acid methyl esters (FAME) and glycerol produced by transesterification reaction contain atoms that in the reagents belong to methanol and, therefore, are not renewable. A method to evaluate the content of the renewable and non-renewable energetic fraction, released during their combustion, was 
developed using a thermochemical criteria, based on bond dissociation energies and the knowledge of the molecular structure of the reagents and the products. Results show that the fraction of non-renewable energy in the most diffused FAME is lower than $1 \%$ depending on the lengths of the carbonaceous methyl esters. Meanwhile, the energetic supply for the GL of this fraction is about $1.6 \%$. The data reported in this document can be used to develop a criteria that corrects the fiscal mechanism aspects of some renewable energy products.

Keywords: Biodiesel, glycerol, renewable energy, bond enthalpy.

\section{List of symbols}

$C_{M E}$ percent composition of $\mathrm{ME}$

$\Delta H_{b}$ bond enthalpy

$\Delta H_{r}$ reaction enthalpy

$\Delta H_{i}$ low calorific value

$\Delta H_{N R}$ enthalpy deriving from the part of the non-renewable molecule

$\Delta H_{C} \Delta H$ values obtained through experiments

$E F_{N R}$ fraction of non-renewable energy of FAME

$N_{S}$ saponification number

$E_{N R}$ fraction of non-renewable energy of the molecule

FAME fatty acid methyl ester

$G L$ glycerol

$H_{E} \quad$ evaporation enthalpy of water

$M E$ methyl ester

$N_{C M}$ average carbon atoms of FAME

$N_{C}$ carbon atoms of FAME 


\section{Professor Giuseppe Stefanelli}

Professor Giuseppe Stefanelli, the illustrious academic of Agricultural Machinery and Rural Building, died in his sleep on the night of 18 October, having only recently celebrated his $104^{\text {th }}$ birthday to the plaudits of his many colleagues and young researchers.

It is no easy task, at this time, to call to mind his numerous accomplishments, both as a man and an academic. The author of this memorial has observed his life and career - although from a distance (Milan) - with the greatest admiration and respect.

Although the Professor was strict with his pupils and a demanding task master, over the years he expressed his enormous goodness of character in both the personal and professional spheres.

I can see even now his good natured smile during the meetings of the Academic Council of the Georgofili Academy as he followed the animated discussions and presentations of his colleagues.

In every case he had a final word to say - a word which invariably agreed with the general opinion of the Councillors. Over the years his character had softened and he was open even to the more naïve interventions of young colleagues. I have two particularly pleasant personal memories of him: the first, when I was presented to him during the Pesaro Agricultural Machinery convention. I recall that my colleague, Professor Casini, warned me at the time to behave myself in a manner suited to the occasion.

The second memory is of the many times he confided to me at the Council of the Georgofili Academy that he would have been pleased to have me as his personal pupil - with that unforgettable smile on his lips.

The Professor was a unique human being, and I deeply regret his loss. If I could speak to him now, I would thank him for having been so patient with me! His human, scientific and cultural capacities will be greatly missed.

(Giuseppe Pellizzi)

\section{CURRICULUM of Professor Stefanelli}

Born in Florence on 11.6.1905, he completed his schooling in classics and went on to a two year physics and mathematics course at the Faculty of Sciences of the city; he received his degree in Engineering from the University of Pisa, and completed his professional studies at Bologna. From 1930 to 1932, he worked at Florence in the areas of civil, agricultural and mechanical engineering.

He went on to work as a voluntary assistant in Agricultural Machinery at the Higher Institute of Agriculture and Forestry, Florence, and then as extraordinary assistant, after which he moved to the Higher Agricultural Institute, Pisa in 1934 as ordinary assistant, and from there to the Engineering Faculty in 1937. He was officially enabled to teach Agricultural Mechanics in 1937 and did so at the University of Perugia.

In 1939 he was elected to Professor of Agricultural Machinery at the University of Pisa, where he directed the faculty of the same name as well as that of Rural Buildings and Topography.

In 1946 he was made Professor and Director of the Faculty of Agricultural Machinery at the University of Bologna, as well as taking charge of the Institutes of Rural Construction, Topography and Agricultural Hydraulics, in which role he continued until 31.10.1965.

On that date he was elected as Professor and Director of Agricultural Machinery at the Institute of Agriculture and Forestry, Florence, where he remained until 31.10.1975 (although he continued his work with the Faculty unofficially for a further five years). He also taught Rural Buildings and Topography at the University from 1965 to 1973.

At the University of Florence he directed the "Programme in tropical and sub-tropical agriculture" from 1972 to 1975; at the same time he presided over the University's Technical Committee for the Agricultural faculty of Somaly (Mogadishu).

In the early years, under the guidance of Professor G. Vitali, and later in collaboration with Professors A. Tarchetti and N. Nerli, he involved in agricultural electrification, with the science of working the soil, and with measuring the work output of oxen (he later constructed two special dynamometer yokes at Bologna). Over the following years he concentrated on theoretical studies in the areas of minimum power requirements for ploughing, the dynamics of tractors and their grip, the proportions between the surface area of farms and the optimal power of tractors, spray irrigation, the working efficiency of tractors, the theory of tracks, the stability of tractors on slopes, soil mechanics and terrain-vehicle systems, accelerations induced in vineyards by grape harvesters, and many others; as well as experimental work in working clay soil with special subsoil chisel plough tools, with rotary and other special equipment, in machinery for breaking up rocky ground, working on slopes, mechanisation in viticul- 
ture, and in particular mechanical harvesters for grapes and olives, equipment for mechanising hemp harvesting (and extraction from debris - from 1950), beetroot (from 1950), cereal crops (from 1954), forage (1964), and spray irrigators, including testing apparaty at the Bologna agricultural faculty, financed by the U.M.A., machines for mechanically dredging clad canals, etc.

He also worked on more advanced subjects, such as the human aspects of mechanisation and professional training, safety and accidents in mechanisation, the state of agricultural engineering in the early 1800's (Centenary of Filippo Re) and Agricultural Machinery in the $19^{\text {th }}$ century and the early 1820's (Studies on the soil mechanics of Antonio Pacinotti; experiments with an antique dynamometer carriage); as well as avant-garde studies in the use of electronic measuring equipment in Agricultural Machinery (1953 onwards) and radio-controlled tractors (a prototype was invented and tested at Bologna in 1959) as well as unmanned programmable tractors (Professors Bosi and Martelli built a Bops prototype which was exhibited at Pesaro in 1960); a large unmanned irrigator called the "Autorain" was built, tested and exhibited at the "Giornate C.I.G.R. - I^ Sez." (Florence, 1972 - Professor Bosi) and was put into service in Puglia (1976-'78).

From 1946 onwards, he also developed informational activities on behalf of the Ministry of Agriculture and Forestry, holding lectures, conferences and training courses, and supervising and directing numerous Agricultural Machinery events (at Pesaro, Bologna, Verona, and elsewhere); he participated in numerous technical congresses and conventions in Italy and abroad (including France, Switzerland, Belgium, Germany, Holland, Australia, Sweden, etc.); and was a member of many research and special Commissions and Committees (Ministry of Education; Ministry of Agriculture; C.N.R.; U.M.A.; U.NA.CO.M.A.; Homologation Committee and others).

In the scientific field of rural construction and topology he was active as a teacher and researcher, and his work was published in various monographs and in a book on the theoretical, technical and practical aspects of rural buildings and two teaching texts (collaboration, 1959 and 1980).

His studies were published in scientific reviews covering a vast range of subjects.

Under his direction, the Perugia Agricultural Machinery Institute was completely reorganised, while the Pisa Institute was designed from the ground up as part of the Faculty's expansion and brought into operation; the Bologna Institute enjoyed a period of great efficiency and was equipped with special instrumentation, including three-axis unit and attachment container for measurements in the soil; electronic instrumentation; dynamometers and torsion meters; for laboratory and field work.

He also organised the mechanical and hydraulics section of the Cadriano experimental sectors of the Bologna Faculty of Agriculture, at which he created the "Bologna centre for homologation of motorised agricultural equipment". The Centre was then expanded and further developed by Professors Manfredi, Casini and Bosi.

In the same period he directed the "orientation bank for spray irrigators" as a service for manufacturers and farmers. In 1965 he went on to direct the Institute of Agricultural Machinery of the University of Florence, created a mechanical laboratory with workshop including electronics. He also made available test fields in the farm and at a large plains farm at Poggio a Caiano (which also operated as an experimental centre for Agricultural Machinery).

In this context we should mention a special electro-hydraulic device (P.T.T.) for field measurements of the soil's resistance to penetration and shear, designed for attaching to a tractor; equipment for unmanned operation of a large self-propelled irrigator. He also developed special equipment for studying crop harvesting (olive and grape) by impact and oscillation; for evaluating the technological qualities of pears and peaches; and for studying models of tools for processing in soil containers equipped with special measurement equipment, among others.

In the fields of experimental Agricultural Machinery and Mechanization he worked for many years with the Ministry of Agriculture and Forestry, with the National Research Council, with the National Agricultural Mechanics Centre of Turin (agronomics section), with the Agricultural Equipment User's Association, and for five years (1963-'67) with the US Department of Agriculture in a study of deep working of clay soil. He worked with numerous authorities, including the Chambers of Commerce of Pesaro and Bologna as technical director of the PesaroTorrette di Fano and Bologna-Ozzano Emilia agricultural mechanics demonstration days, and the associated conventions on special subjects in Agricultural Mechanization and Engineering.

In particular, he took part in the "C.N.R. special programme for mechanisation of farming - 1966/"70" as President of the Interdisciplinary Commission on "Harvesting and collecting forage in the farms of Tormancina and Maccarese" and as Director of the Agricultural Machinery section of the Commission and its section for the "Mechanization of the Castel di Pietra farm".

As a member of the Select Committee for the feasibility study for the "Finalised C.N.R. programme for Agricultural Mechanics", he was Director of the C.N.R. Unit at the Institute of Agricultural Machinery, Florence for the "Mechanisation of grape harvesting" programme and the associated experimental work in Tuscany during the period 1976-'80.

From 1978 he was President of the Scientific Council of the "C.N.R. Soil Colloids Centre" and the "C.N.R. Autotroph Centre". 
In 1976, as an effective member, he took part in the "Technical Commission on the development of scientific and training facilities in Le Marche with the aim of instituting a State University of Agriculture in the Le Marche Region"

He represented Italy in the Comité directeur de la Commission internationale du Génie rural (C.I.G.R.) of Paris (1967-'76) and Vice-President of the IIIrd Section (Agricultural Machinery) of the Commission itself (1969'74). He was emeritus member of the Georgofili Academy of Florence; ordinary member of the National Academy of Agriculture, Bologna; honorary academic of the Pesaro Agricultural Academy, of the Siena Vine and Wine Academy (1984) and the Italian Forestry Sciences Academy (1984). He was also a correspondent and later ordinary member (1985) of the Turin Agricultural Academy; correspondent (from 1969) and then ordinary member (1982) of the Academie d'Agriculture de France; member of SITMA (Soc. de ingenieurs et techniciens du machinisme agricole); member of the Institut international des recherches betteravières (Belgium); of ASAE (American society of agricultural engineering) - U.S.A.; founding member of the International society for terrain-vehicle systems - U.S.A.; effective President (1967-'76) and honorary (from 1976) of the Italian Agricultural Engineering Association (A.I.G.R.), and honorary member of C.I.G.R. (from 1984).

He was elected Vice-President of the Georgofili Academy in 1970; from February 1977 he acted as its President and from 1977 was elected as such (confirmed for three years in 1979 and for a further three year term in 1982).

He was member of the Italian Society for Soil Sciences and President (1966-'76) of its Vth Commission; also member of the National Committee for Experimental Agriculture of M.A.F. (1975-'78).

He was awarded the "Spiga d'oro" (Rome, 1963), "Torello d'oro" Gi\&Gi (Rome, 1965), the Fondazione Marchi Prize for agricultural progress (Florence, 1972), the ten-year prize "for merit in agricultural technology”, promoted by the National Federation Agricultural Sciences Graduates (Foggia, 1979).

Since 1977 he was a permanent member and from 1978 President of the said Foundation's Scientific Commitee. From 1980 he has been on the Roll of Honour of the Order of Engineers and Architects of the Province of Florence; and Commander of the Order of Merit of the Italian Republic (1981); he was awarded the title of Emeritus Professor by the President of the Republic (19.12.1985).

He was President of the Georgofili Academy from 1977 to 1986, and then elected Commissioner of the Acts, member of the Academic Council and Honorary President. 